\title{
Jonas Salk (1914-1995): A vaccine against polio
}

\author{
Siang Yong $\underline{\operatorname{Tan}}^{1}, \mathrm{MD}, \mathrm{JD}$, Nate $\underline{\text { Ponstein }}^{2}, \mathrm{MD}$
}

T hose who lived through the 1940s and 1950s will not forget the devastating ravages of poliomyelitis, a spinal cord motor neuron disease caused by the poliovirus. Indeed, the mere mention of the virus quickly evokes heartwrenching images of crippled children in leg braces, or an infant trapped in a sarcophagus-like breathing machine known as the 'iron lung'. However, the poliovirus is on the verge of global eradication today - an astounding achievement of modern medicine. Jonas Salk played a pivotal role in achieving this success by being the first to devise and implement a safe and effective vaccine against polio.

THE HUMAN SIDE OF NATURE Jonas Salk was born in New York City, New York, United States (US), to an Orthodox Polish-Jewish immigrant family on 28 October 1914. His parents lacked the benefits of a formal education, so they actively encouraged Jonas and his siblings to focus on their studies. After completing high school, Jonas matriculated at the City College of New York, and became the first member in the family to obtain a college education. However, it was law, not science, that initially kindled his academic interest. While growing up, Salk showed little affinity for the didactic aspects of the natural sciences, but his words belied a deep-rooted respect for human biology. "As a child," he wrote, "I was not interested in human anatomy. I was merely interested in things human, the human side of nature, if you like, and I continue to be interested in that. That's what motivates me.

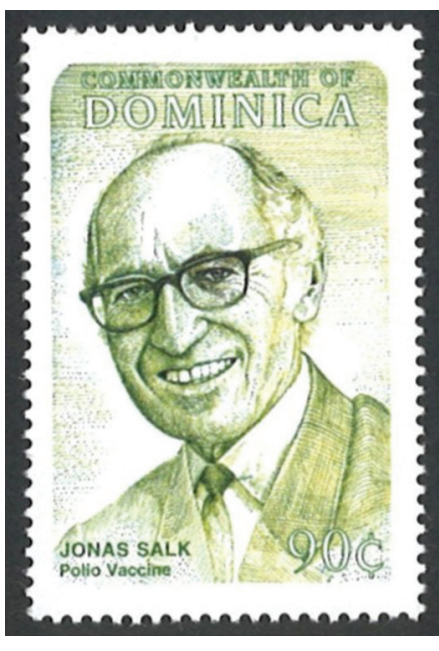
And in a way, it's the human dimension that has intrigued me."

Salk was deterred from a career in law when his mother insisted he could never succeed in a courtroom if he could not even win an argument with her. He later found himself impressed with the combination of science and the humanities, and switched his academic focus from pre-law to pre-med. He studied medicine at the New York University School of Medicine and dabbled in research involving the influenza virus as a medical student. Upon graduation, Salk obtained a prestigious research fellowship at the University of Michigan, Michigan, under the direction of Dr Thomas Francis. The pair worked towards the development and implementation of an effective influenza vaccine for the US military, which was entrenched in World War II at the time. Following the completion of his fellowship, Salk turned his attention to the poliovirus in a similar search for an effective and safe vaccine. He began his work at the University of Pittsburgh,
Pennsylvania, and there set the stage for one of the most heralded medical breakthroughs in the history of medicine.

A DIFFERENT PARADIGM In 1947, Salk was appointed director of the Virus Research Laboratory at the University of Pittsburgh School of Medicine. At the time, the established paradigm of vaccine development was to first isolate a 'live' but weakened micro-organism. This attenuated virus or bacteria would then be administered to patients in order to create a low-grade, innocuous infection that would confer long-standing immunity. However, Salk had employed an alternative approach in his prior work on the influenza vaccine. He had used noninfectious killed viruses to induce protective immunity. Despite the discouragement of his peers and detractors, he decided to take the same approach in his polio research.

Salk had written a number of scientific and theoretical articles regarding polio and the merits of a killed virus vaccine. His publications eventually captured the attention of the National Foundation for Infantile Paralysis, a charitable organisation first established by US President Franklin D Roosevelt to raise money for poliomyelitis research. This foundation, now widely known as the March of Dimes, provided ample financial support for Salk's research and helped to jump-start his efforts towards a vaccine goal.

THE VACCINE Salk and his team used formaldehyde to kill the poliovirus without destroying its antigenic properties. After establishing both safety and efficacy, they administered the vaccine to scores of volunteers, including himself, his wife and their children. In 1954, Salk undertook a large-scale national study, enrolling over one million paediatric subjects. The next year, on 12 April 1955, he announced the results: the vaccine was both safe and efficacious. Subsequent data showed that in 1955, there were approximately 29,000 cases of poliomyelitis in the US. Just two years after mass production and implementation of the newly developed vaccine, the infection rate plummeted to less than 6,000. The Salk vaccine was quickly adopted nationwide, and by 1959, had reached about 90 countries.

Despite his momentous work, Salk was conspicuously snubbed for membership in the American Academy of Sciences and was never awarded a Nobel Prize. He is said to have trivialised the contributions of other scientists that preceded him and even downplayed the efforts of his own research team. For

${ }^{1}$ Emeritus Professor of Medicine, University of Hawaii, ${ }^{2}$ Research carried out during medical residency, John A Burns School of Medicine, University of Hawaii, Honolulu, Hawaii, USA Correspondence: Prof Tan Siang Yong, 2226 Liliha Street, Suite B-104, Honolulu, HI 96817, USA. siang@hawaii.edu 
example, in 1948, Dr John Enders and his colleagues Dr Thomas $\mathrm{H}$ Weller and Dr Frederick Robbins successfully cultivated the poliovirus in human tissue in the laboratory, for which they won the Nobel Prize in 1954. This development greatly facilitated vaccine research and ultimately allowed for the development of vaccines against polio. Another important advance that led to the development of polio vaccines was the identification of three different poliovirus serotypes.

PARALYSIS AND THE SABIN VACCINE Shortly after mass polio vaccination began in the US, some subjects developed paralysis in the limb where the vaccine had been administered. Preparations from Cutter Laboratories and, to a lesser extent, Wyeth Laboratories were implicated and the vaccine was recalled after 250 cases of paralytic illness had occurred. There were also reports of paralysis and death in several children. Investigations showed that improperly inactivated vaccine had released live virus into more than 100,000 doses of the vaccine.

At around this time, Dr Albert Sabin and Dr Hilary Koprowski were working on an attenuated live poliovirus vaccine. In 1955, they presented their preliminary work at a meeting in Stockholm, Sweden, and conducted trials outside the US, such as in Mexico and the Soviet Union, because the US had committed itself to the Salk vaccine. In 1957, Dr Sabin developed a trivalent oral vaccine consisting of attenuated strains of all three types of the poliovirus, which was then given to ten million children in the Soviet Union. For this work, Dr Sabin, who was originally from Polish Russia, was awarded the Soviets' highest civilian honour, the medal of the Order of Friendship Among Peoples, even though he had become an American citizen during the height of the Cold War. Their oral vaccine came into commercial use in 1961 and quickly replaced Salk's injected vaccine, which had suffered a loss of public confidence as a result of the Cutter-Wyeth debacle.

PERSONAL LIFE AND LEGACY While in college in New York, Salk met his first wife, Donna Lindsay, whom he married in 1939. Together they had three children, Peter, Darrell and Jonathan, who ultimately pursued their own medical and research careers. In 1965, Jonas Salk moved to La Jolla, California, and founded the Salk Institute for Biological Studies, which remains one of his most enduring legacies. The institute was established to provide an environment of creativity where researchers could "work together to explore the wider implications of their discoveries for the future of humanity". Many talented scientists were attracted to La Jolla, with the institute's first faculty consisting of the likes of Dr Francis Crick, the co-discoverer of the DNA double helix.

In 1968, Salk's first marriage ended in divorce. Shortly thereafter, he met the French artist Françoise Gilot, a former mistress of Pablo Picasso, and they were married in 1970. He found a rare combination of artistry, intellect and companionship in Gilot, and remained in La Jolla with his new wife for the remainder of his career until his death from heart failure in 1995. An interviewer once inquired about the ownership of the polio vaccine patent, to which Salk famously answered, "Well, the people, I would say. There is no patent. Could you patent the sun?" It was this spirit of humanism in combination with his astounding accomplishments in virology and vaccine development that have permanently etched Salk into the annals of medical history.

Polio was eliminated from North America by 1994 and in most countries worldwide shortly thereafter. Still, unlike smallpox, polio has not been entirely wiped out. As recently as 2013, Syria witnessed an outbreak, and the disease has now spread to some ten countries in Africa, Asia and the Middle East. Deep-seated distrust stemming from religious and racial origins has led to resistance towards vaccination programmes and even violent attacks on health workers. In 2011, the Central Intelligence Agency organised a fake vaccination programme in the search for Osama bin Laden. This tactic helped to fuel the misconception that the vaccine causes infertility in male children, which unfortunately prompted some parents to forgo vaccinating their children.

\section{BIBLIOGRAPHY}

- Wikipedia. Jonas Salk. Available at: https://en.wikipedia.org/wiki/Jonas_Salk. Accessed December 18, 2018.

- The Salk Institute. Available at http://www.salk.edu. Accessed December 18, 2018.

- Salk JE. Poliomyelitis vaccination in the fall of 1956. Am J Public Health Nations Health $1957 ; 47: 1-18$.

- Smithsonian National Museum of American History. Whatever Happened to Polio? [online] Available at: http://americanhistory.si.edu/polio/. Accessed December 18, 2018.

- Spice B. Developing a medical milestone: the Salk polio vaccine. The Salk vaccine: 50 years later/First of two parts [online]. Pittsburgh PostGazette 2005 Apr 3. Available at: https://www.post-gazette.com/news/ nation/2005/04/03/Developing-a-medical-milestone-the-Salk-polio-vaccine/ stories/200504030276. Accessed December 18, 2018.

- Spice B. Tireless polio research effort bears fruit and indignation. The Salk vaccine: 50 years later/second of two parts [online]. Pittsburgh PostGazette 2005 Apr 3. Available at: https://www.post-gazette.com/news/ world/2005/04/04/Tireless-polio-research-effort-bears-fruit-and-indignation/ stories/200504040195. Accessed December 18, 2018.

- YouTube. Sicko DVD Extra Preview - Interview Gallery. Available at http:// www.youtube.com/watch?v=QHGKLbDt_2Q\&eurl=http://www.michaelmoore. com/sicko/dvd/extras.html 